\title{
Evaluasi kualitas estetika tanaman lanskap jalan Ahmad Yani Kota Pontianak
}

\author{
Hablul Bahri๋, Agus Ruliyansyah, M. Pramulya \\ Prodi Agroteknologi, Fakultas Pertanian, Universitas Tanjungpura, Indonesia \\ *E-mail: hablulbari@gmail.com
}

\begin{abstract}
Evaluation Aesthetic Quality of Plant Landscape Ahmad Yani Street Pontianak City. Ahmad Yani street is one of the streets located in downtown Pontianak. This road every day in passed by road users, be it a motorcycle or car and pedestrian. Structuring roads and plants continue to be done in accordance with its function.The purpose of this research is to evaluate to analyze the aesthetic quality of landscape plants and to formulate recommendations in improving or maintaining the quality of plant aesthetics. The method used in this research is survey, interview and questionnaire. Data analysis was processed through statistical questionnaires by means of SBE calculations by grouping based on the rating scale 1 to 10 . The results stated assessment of aesthetic qualities with high grade SBE values is caused by neatly arranged plants and has a very attractive shape. The value of SBE with the medium category obtained from the form of an interesting plant but around the plant there is a pole or bulletin board that makes the scene less attractive. While the value of low category SBE is caused by plants that are not neatly arranged and the form of plants that are less interesting.
\end{abstract}

\section{Keywords: Evaluation, SBE, Ahmad Yani street, Pontianak City}

\section{Pendahuluan}

Jalan Ahmad Yani adalah salah satu jalan yang terletak di pusat Kota Pontianak. Sekolah, pusat perbelanjaan dan bisnis berada disepanjang jalan jenderal ahmad yani. Sebagian besar dari kantor pemerintahan juga berada di jalan pusat kota ini seperti kantor Gubernur, kantor DPRD Provinsi dan kantor lainnya. Jalan Jenderal Ahmad Yani diperuntukkan sebagai car free day di akhir pekan tempat untuk berolahraga, berjualan dan lainnya.

Jalan Ahmad Yani setiap harinya di padati dengan kendaraan, baik itu sepeda motor maupun mobil dan pejalan kaki. Dengan banyaknya masyarakat yang menggunakan jalan ini maka diperlukan penataan jalan yang baik seperti pemilihan tanaman yang berfungsi sebagai pembatas jalan, peneduh, penyerap polusi udara, pemecah angin, pembatas pandang maupun tanaman yang berfungsi untuk menambah keindahan jalan agar membuat masyarakat merasa nyaman.

Setelah 2 tahun terakhir Jalan Ahmad Yani masih dalam proses penataan. Baik dalam penataan jalan maupun penataan tanaman. Penataan tanaman dilakukan sesuai dengan fungsinya masing-masing. Tanaman yang berada di sepanjang Jalan Jenderal Ahmad Yani bermacam-macam. Dengan keberagaman tanaman tersebut diperlukan perhatian yang cukup besar sehingga evaluasi menjadi penting untuk dilakukan.

Evaluasi tanaman lanskap jalan perlu dilakukan untuk mengoptimalkan fungsi tanaman pada jalan. Evaluasi tanaman lanskap juga dapat dilengkapi dengan penilaian kualitas estetika. Oleh karena itu penelitian ini bertujuan untuk mengevaluasi fungsi dan nilai estetika tanaman lanskap dengan melibatkan sejumlah responden. Diharapkan dengan adanya penelitian ini dapat menjadi acuan pihak terkait dalam proses perancangan ataupun pemeliharaan tanaman lanskap di jalan Jenderal Ahmad Yani kota Pontianak Kalimantan Barat.

\section{Metode}

Penelitian dilaksanakan di Jalan Ahmad Yani Kota Pontianak Kalimantan Barat. Penelitian ini dilakukan selama empat bulan dari September-Desember. Metode yang digunakan pada penelitian ini 
menggunakan teknik survey,wawancara dan kuesioner. Pelaksanaan evaluasi dilakukan dengan tahapan: (1) studi literatur (2) evaluasi kondisi tanaman (3) evaluasi kualitas estetika tanaman (4) analisis data dan (5) rekomendasi. Responden adalah mahasiswa yang telah mengambil mata kuliah Lanskap karena dianggap lebih memahami konsep penilaian. Proses penilaian dilakukan dengan mengumpulkan mahasiswa pada satu ruangan kemudian diberikan lembar keusioner penilaian. Data yang sudah diperoleh kemudian di analisis melalui lembar kuesioner secara statistik dengan cara perhitungan SBE dengan pengelompokkan berdasarkan skala penilaian 1 sampai dengan 10 . Tiap peringkat nilai dihitung frekuensi kumulatif, peluang kumulatif, nilai $Z$ dan nilai $Z$ rata-rata, kemudian ditentukan satu nilai $Z$ dari foto lanskap tertentu sebagai lanskap standar nilai Z yang paling mendekati nol. Nilai SBE diformulasikan sebagai berikut :

$$
\operatorname{SBE}_{x}=\left(Z L_{x}-Z L_{s}\right) \times 100
$$

$$
\begin{aligned}
& \mathrm{SBE}_{\mathrm{x}}=\text { Nilai } \mathrm{SE} \text { lanskap ke } \mathrm{x} \\
& \mathrm{ZLx}=\text { Nilai rata-rata } \mathrm{Z} \text { lanskap ke } \mathrm{x} \\
& \mathrm{ZL}_{\mathrm{s}}=\text { Nilai rata-rata lanskap standar }
\end{aligned}
$$

Dari nilai SBE yang diperoleh selanjutnya setiap objek dapat dikelompokkan menjadi nilai keindahan tinggi, sedang dan rendah. Pengelompokkan ini dilakukan dengan menggunakan sebaran normal. Seluruh nilai SBE dirata-rata kemudian dihitung ragam dan simpangannya sehingga dapat dibuat selang kepercayaan untuk mengelompokkan lanskap kedalam keindahan pemandangan tinggi, sedang dan rendah.

\section{Hasil dan Pembahasan}

3.1 Penilaian SBE

Berdasarkan penilaian dari responden yang berupa data kuesioner menghasilkan nilai SBE yang bervariatif. Responden yang terdiri dari 40 orang mahasiswa yang telah mengambil mata kuliah lanskap memberikan penilaian yang berbeda-beda. Hasil SBE seluruh foto lanskap dapat dikategorikan menjadi keindahan pemandangan tinggi, sedang dan rendah. Pengelompokkan penilaian kualitas estetika dapat dilihat pada tabel berikut.

. Tabel 1. Penilaian Kualitas Estetika Tanaman

\begin{tabular}{cccc}
\hline Responden & & Kategori & \\
& Tinggi & Sedang & Rendah \\
& & & Lanskap: \\
\hline Mahasiswa yang telah & Lanskap: & Lanskap: \\
mengambil mata kuliah & $3,4,9,11,12$, & $6,8,10,14,15,18$, & $1,2,5,7,17,20,21$, \\
lanskap & $13,16,39,40$ & $19,23,24,30,31$, & $22,25,26,27,28,29$, \\
& & $32,34,35,36,37,38$ & 33 \\
\hline
\end{tabular}

\subsubsection{Keindahan Pemandangan Tinggi}

Penilaian dengan kategori tertinggi dari kelompok responden terlihat pada lanskap 39. Nilai tertinggi yang diberikan oleh responden untuk lanskap 39 adalah 114,245. Lanskap tersebut mendapat nilai tertinggi dikarenakan posisi tanaman tersusun sangat rapi dan mempunyai bentuk yang sangat menarik sehingga membuat orang yang melintas merasa nyaman. Selain gambar 39 yang termasuk dalam klasifikasi keindahan yang tinggi adalah gambar 3, 4, 9, 11, 12 13, 16 dan 40. Menurut Daniel dan Boster (1976) lanskap yang memiliki nilai pendugaan estetika tertinggi merupakan lanskap yang paling disukai atau indah. 

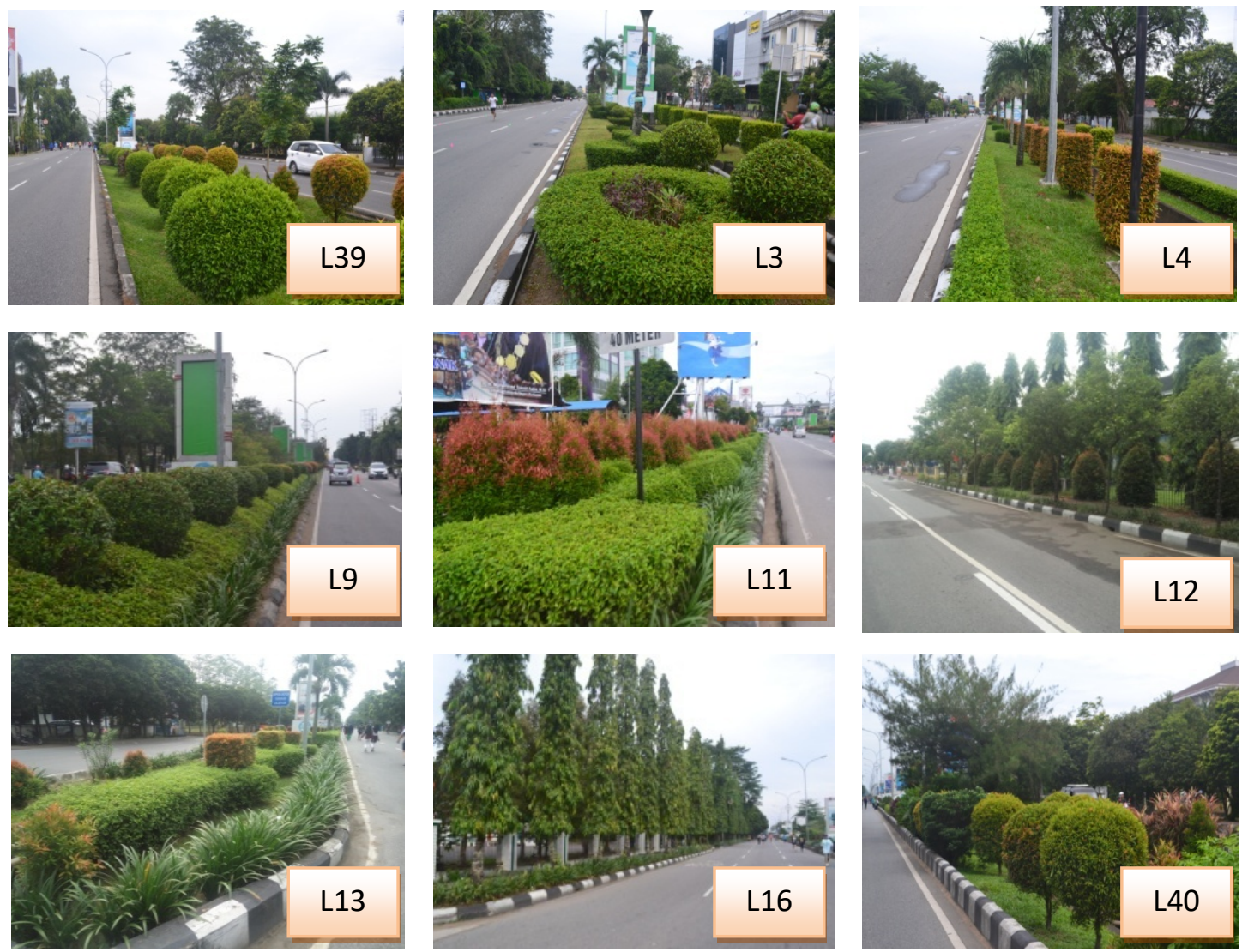

Gambar 10. Lanskap dengan penilaian tertinggi

\subsubsection{Keindahan pemandangan sedang}

Penilaian untuk katagori sedang dari responden terlihat pada lanskap 6, 8, 10, 14, 15, 18, 19, 23, 24, $30,31,32,34,35,36,37$ dan 38. Umumnya tanaman pada kategori sedang masih kelihatan menarik namun ada sebagian tanaman yang kurang tertata rapi. Tiang dan papan pengumuman juga bisa menjadi penyebab kurangnya nilai estetika dari suatu lanskap. Contoh seperti pada lanskap 6 bisa dilihat tanaman sudah tersusun rapi namun tampak tiang ataupun papan yang membuat lanskap menjadi kurang indah. Tanaman pada lanskap jalan raya memiliki peran yang cukup besar. Carpenter, et. al. (1975) mengemukakan bahwa kehadiran tanaman di lingkungan perkotaan memberikan suasana alami. Daun-daun hijau tanaman dengan berbagai tekstur dan bayangan yang ditimbulkan oleh pohon menghadirkan kelembutan serta kesegaran pada areal beraspal. Tanaman juga dapat menetralkan suasana tertekan akibat temperatur tinggi, polusi udara serta suasana bising. Jalur hijau tepi jalan dapat dijadikan suatu tempat rekreasi dan berolahraga bagi masyarakat kota. Suasana rutin dan sibuk yang terlihat setiap hari di perkotaan dapat berubah menjadi lebih santai dengan keindahan dan kenyamanan yang dihadirkan oleh tanaman di jalur hijau. 

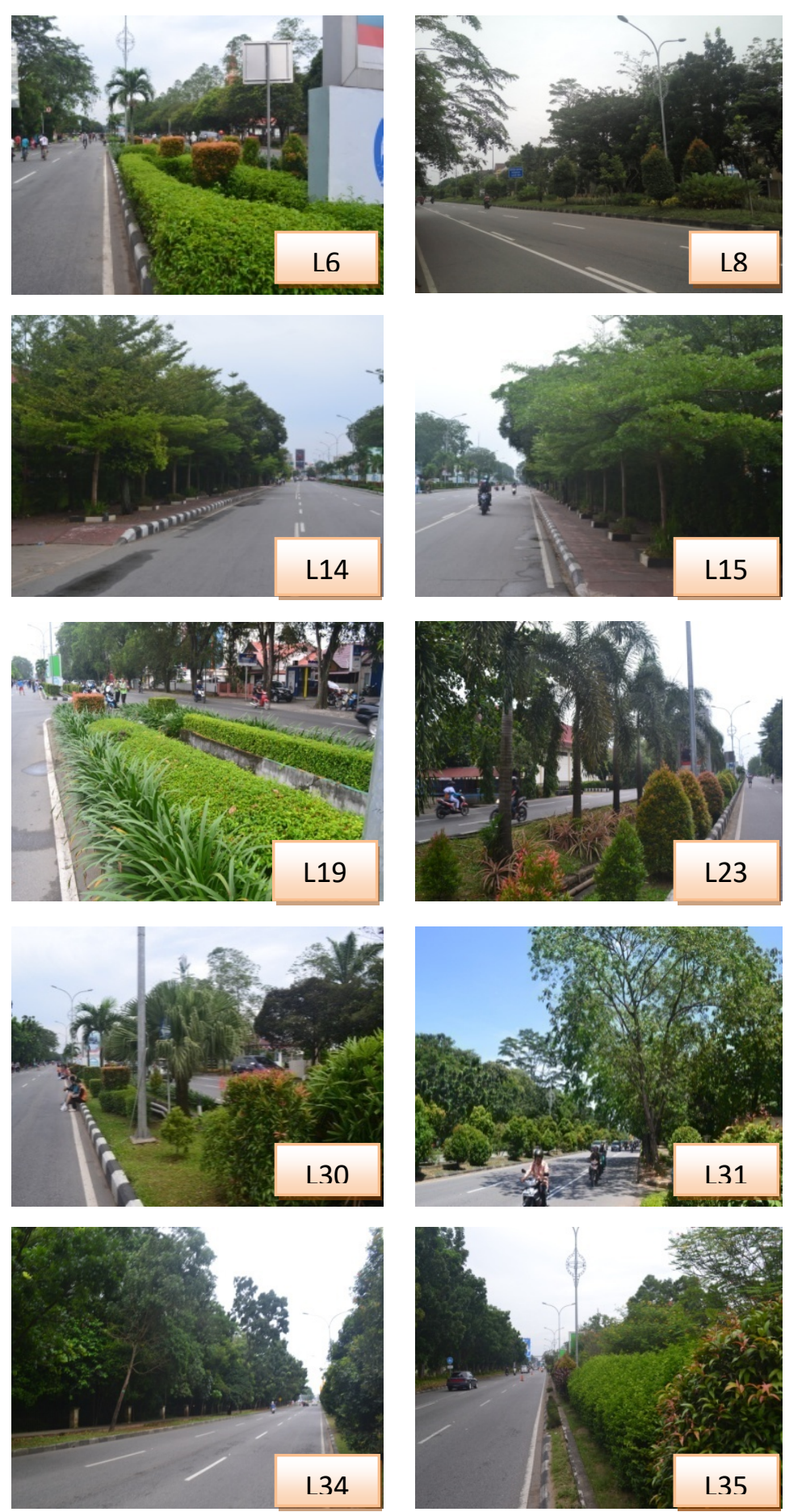

L35
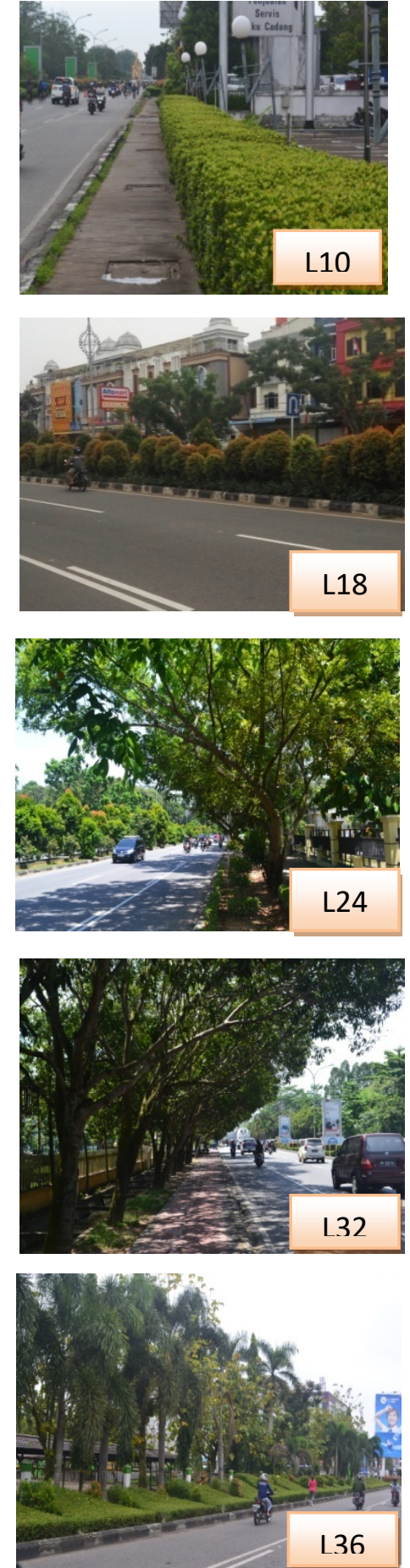

L36
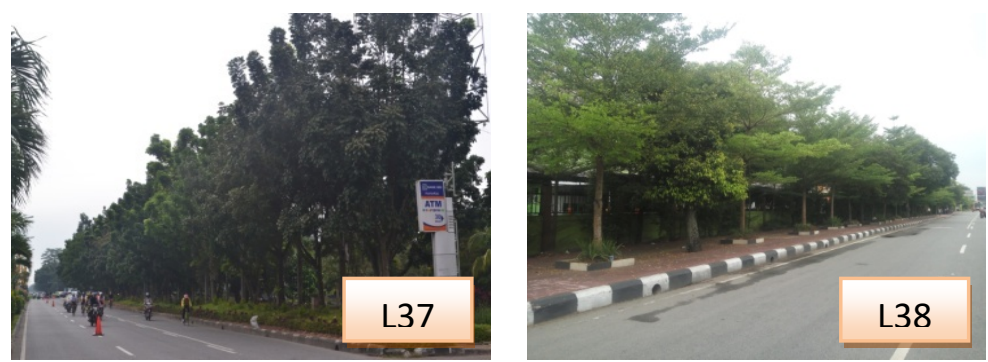

Gambar 11. Lanskap dengan Penilaian Sedang 


\subsubsection{Keindahan pemandangan rendah}

Penilaian untuk katagori rendah dari responden terlihat pada lanskap 22 . Nilai terendah yang diberikan pada lanskap 22 oleh responden dengan nilai SBE -11,2859. Penilaian tersebut dikarenakan penampilan tanaman yang tidak tersusun dengan rapi dan kurang menarik. Pada lokasi tersebut jenis pohonnya memiliki tajuk dan cabang yang sederhana.
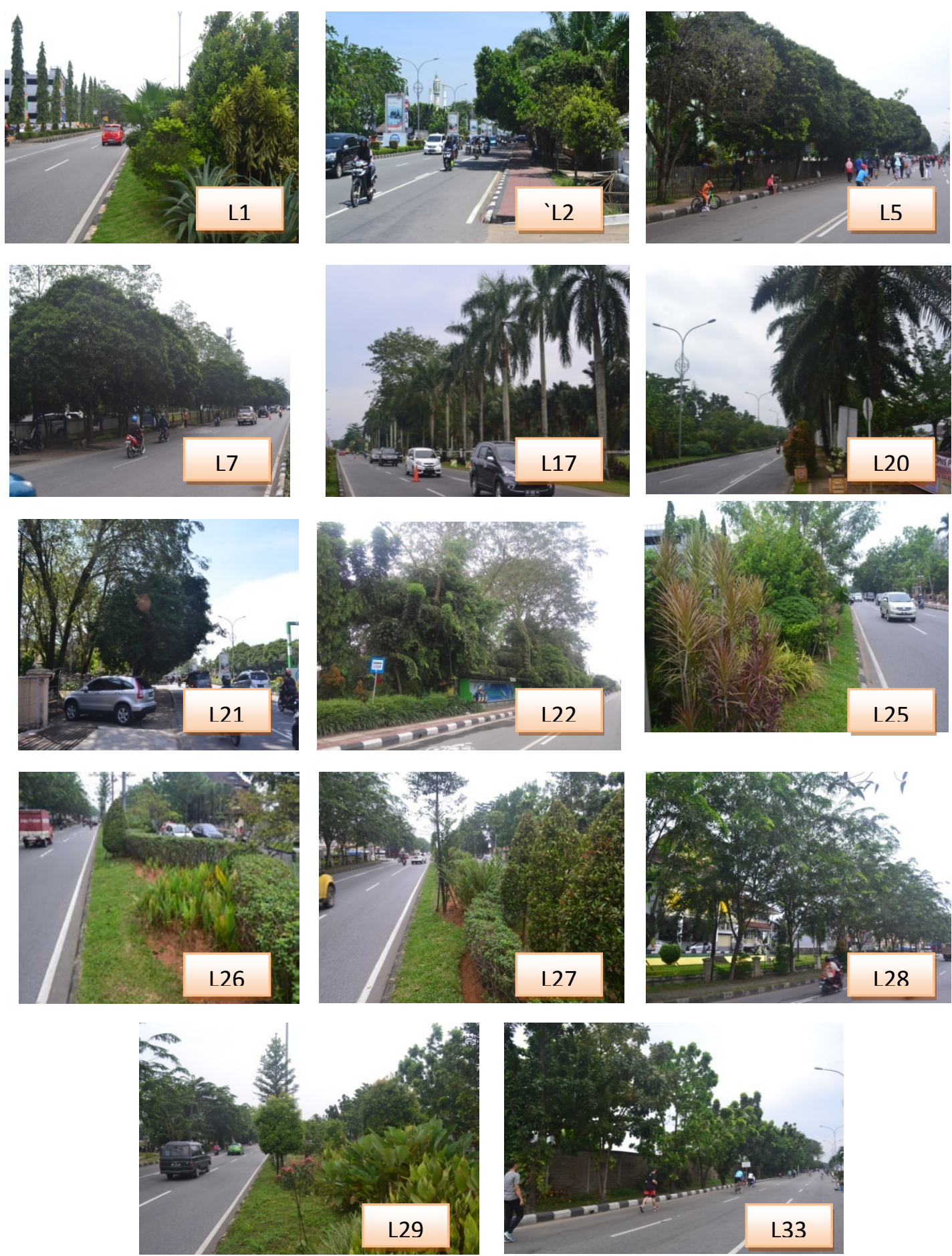

Gambar 12. Lanskap dengan Penilaian Rendah 
Dapat dilihat di lanskap 1 tanaman tidak tersusun rapi dan mempunyai bentuk yang kurang menarik. Lanskap tanaman yang termasuk dalam penilaian rendah lainnya adalah lanskap 1, 2, 5, 7, 17, 20, 21, 22, $25,26,27,28,29$ dan 33. jalan harus memberi kesan yang menyenangkan dari setiap pergerakan, dimana akan berguna dan menyenangkan bagi pemakai jalan jika terdapat keharmonisan dan kesatuan dengan karakteristik lanskap yang ada sehingga fungsional secara fisik dan visual (Simonds, 1983).

\subsection{Rekomendasi Kualitas estetika tanaman}

\subsubsection{Rendah}

Hasil penilaian kategori rendah harus ditingkatkan dengan cara melakukan penanaman ulang tanaman, memilih kombinasi tanaman yang tepat, menyusun tanaman secara rapi atau membentuk suatu pola tertentu. Selain itu, penempatan tanaman tidak boleh menumpuk pada satu bagian.

\subsubsection{Sedang}

Hasil penilaian kategori sedang perlu ditingkatkan dengan cara melakukan penambahan kombinasi tanaman yang sesuai, merapikan posisi tanaman dan membentuk pola tanaman agar terlihat unik sehingga membuat kesan menarik dan nyaman untuk dipandang.

\subsubsection{Tinggi}

Hasil penilaian dengan kategori tinggi harus tetap dipertahankan. Penampilan tanaman dijaga dengan cara melakukan pemeliharaan efektif, menjaga bentuk dan struktur tanaman. Lingkungan tumbuh tanaman juga perlu dipertahankan agar keindahan tanaman tetap menonjol dan menciptakan kesan menarik perhatian.

\section{Simpulan}

Penilaian kualitas estetika dengan nilai SBE kategori tinggi disebabkan oleh tanaman yang tersusun rapi dan mempunyai bentuk yang sangat menarik. Nilai SBE dengan kategori sedang didapat dari bentuk tanaman yang menarik namun disekitar tanaman ada tiang ataupun papan pengumuman yang membuat pemandangan menjadi kurang menarik. Sedangkan Nilai SBE kategori rendah disebabkan oleh tanaman yang tidak tersusun rapi dan bentuk tanaman yang kurang menarik. Rekomendasi yang dibutuhkan dilihat berdasarkan nilai fungsi dan nilai estetika yang sudah ada. Kategori rendah, sedang dan tinggi adalah acuan berapa banyak aspek yang harus diperbaiki.

\section{Daftar Pustaka}

Carpenter, P.L., T.D. Walker and F.O. Lanphear. 1975. Plants in the Landscape. W.H. Freeman and Company. New York.

Daniel, T.C. and R.S Boster. 1976. Measuring Landsape Aesthetic: The Scenic Beauty Estimation Method. US For., Serv., Res., Pap., RM-167.

Simonds, J.O. 1983. Landscape Architecture. Mc.Graw-Hill, Inc. United States of America. 